\title{
Metáforas do cérebro: uma reflexão sobre as representações do cérebro humano na contemporaneidade
}

| ${ }^{1}$ Felipe Stephan Lisboa, ${ }^{2}$ Rafaela Teixeira Zorzanelli |

Resumo: Neste trabalho pretendemos apresentar e debater algumas metáforas do cérebro humano presentes numa amostra de materiais de divulgação científica visando, com isso, refletir sobre sentidos e usos associados ao cérebro humano. No caso da divulgação científica, em que cientistas ou jornalistas científicos buscam traduzir ou recriar para o público leigo o conhecimento científico, a importância das metáforas é evidente porque estas aproximam o público leigo de certos sentidos atribuídos pelos divulgadores sobre o funcionamento do cérebro. Discutiremos analiticamente, por fim, alguns pontos de contato entre as metáforas encontradas.

Palavras-chave: metáforas; cérebro; neurociências; divulgação científica.
1 Divisão Psicossocial Universidade Federal de Viçosa. Viçosa-MG, Brasil. Endereço eletrônico:

felisboa02@hotmail.com

2 Departamento de Políticas e Instituições de Saúde, Instituto de Medicina Social da UERJ. Rio de Janeiro-RJ, Brasil. Endereço eletrônico: rtzorzanelli@yahoo.com.br

Recebido em: 03/12/2013 Aprovado em: 11/06/2014 
- Eu compreendo — disse o Homem de Lata - Mas, afinal de contas, o cérebro não é a melhor coisa deste mundo. - Você tem cérebro? - quis saber o Espantalho. - Não. Minha cabeça é completamente oca. Mas um dia já possui um cérebro e um coração. E, por ter experimentado os dois, é que prefiro o coração.

Trecho do filme $O$ Mágico de $O Z$

Se olharmos para os séculos recentes, veremos que o cérebro foi descrito como uma máquina hidrodinâmica, um relógio e um motor a vapor. Quando eu era criança, nos anos 50, li que o cérebro humano era uma central telefônica. Depois, ele se tornou um computador. Recentemente, alguém me fez a pergunta que eu esperava havia anos: "O cérebro humano é como a internet?". O cérebro sempre parece ser a mais avançada tecnologia que nós, humanos, dispomos em determinado momento. As metáforas que usamos no passado não resistiram, $e$ duvido que a metáfora atual — de uma rede de computadores — resista por muito tempo. [...] Suspeito que, em algum momento, ainda criaremos metáforas melhores e menos computacionais, que poderão ter implicaçôes importantes em nossa capacidade de entender o mundo.

Rodney Brooks, especialista em inteligência artificial do MIT.

\section{Introdução}

As epígrafes acima ilustram dois aspectos que interessam diretamente a este artigo: as diferentes metáforas associadas ao órgão que anima a mente, seja o coração ou o cérebro, e os diferentes deslizamentos de sentido que o cérebro vem recebendo das mais variadas fontes, desde a literatura científica, passando pelas produçôes de divulgação científica, dentre outras. O objetivo do presente trabalho é apresentar e debater, de forma exploratória, algumas metáforas sobre o cérebro e seu funcionamento encontradas em materiais de divulgação científica, visando, com isso, refletir sobre as representaçôes do cérebro humano na contemporaneidade. Para tanto, nos amparamos em algo que a literatura nacional e internacional tem demonstrado, que é a ascensão do cérebro como lugar privilegiado, senão exclusivo, de origem da mente, dos comportamentos, das escolhas e desejos (VIDAL, 2005; ORTEGA; VIDAL, 2007). Os textos de divulgação científica da amostra foram escolhidos tendo como critério serem dirigidos à população leiga - com vocabulário e conteúdo para atingirem o grande público, em língua portuguesa, e a partir dos anos 2000. O propósito era, diante da amostra de material avaliado, apresentar como o cérebro é metaforizado 
nos textos de vulgarização da ciência e o desdobramento disso sobre as atribuições

de sentido a ele associadas no campo de ligação entre a ciência e o saber leigo, cada vez mais estreito nos dias de hoje.

Por metáforas entendemos, seguindo Coser (2010, p. 11), o "conjunto de recursos simbólicos e imagéticos" utilizados para se referir ao cérebro e seu funcionamento. Como afirma esse autor, diante da impossibilidade de conhecermos a coisa em si, operamos por meio de imagens, representaçôes, fantasias e metáforas - sempre datadas e circunscritas, diga-se de passagem. De forma mais simples, conforme aponta Sontag (2007) a partir de Aristóteles, metáfora pode ser entendida como o ato de dar a uma coisa o nome de outra. Ainda segundo ela, "é impossível pensar sem metáforas" (SONTAG, 2007, p. 81). Talvez possamos dizer, acrescentando à autora, que é impossível - ou muito difícil - fazer ciência e, especialmente, divulgar ou popularizar ciência, sem fazer uso de metáforas.

Como afirma Contenças (1999, p. 9), "o conhecimento científico não é independente da linguagem em que é apresentado. As palavras não são neutras em relação aos factos, mas fazem uma seleção do que é considerado importante e ajudam a 'dar forma' àquilo que aceitamos dos objetos científicos". Segundo a autora, as expressões figurativas, dentre elas as metáforas, permeiam a ciência, desde os momentos iniciais de elaboração/construção dos fatos científicos até sua comunicação/divulgação. Para ela, a perspectiva neopositivista de que a linguagem científica deve ser objetiva e neutra e, portanto, descartar toda subjetividade e fantasia, não se sustenta. Segundo ela, a história das ciências demonstra que desde sempre a linguagem científica inclui expressōes metafóricas, seja de forma explícita ou implícita. A própria terminologia científica tem, algumas vezes, uma origem metafórica.

No caso da popularização/divulgação científica, em que cientistas ou jornalistas científicos buscam traduzir ou recriar para o público leigo o conhecimento científico, a importância das metáforas é evidente. Ainda segundo Contenças (1999, p. 75), no processo de comunicação científica, a metáfora tem papel essencial na "tradução de uma linguagem mais específica para uma linguagem mais ampla, capaz de ser entendida por um público alargado". Por exemplo, no Guia prático de divulgação científica, Malavoy (2005) aponta que os bons divulgadores se utilizam de tal ferramenta linguística com frequência, em função de seu poder de evocação que colore o texto com imagens que marcam os leitores. 
O autor alerta, no entanto, que apesar de ser uma ferramenta indispensável, é preciso ficar atento para o risco do abuso de metáforas, que pode transformar o texto de divulgação em algo "pesado e irritante”. Malavoy (2005, p. 45) conclui com a seguinte indicação: "não se esqueça de aterrissar após seus voos líricos". Se nos arriscamos ainda a pensar que as palavras são sempre o uso de que se faz delas, as metáforas, ou seja, os sentidos atribuídos, as formas de apropriação, as oscilações nos significados podem nos esclarecer, em muito, o valor deste órgão em voga, o cérebro, na explicação de formas de comportamentos, escolhas morais e, sobretudo, formas de sofrimento mental.

Já no caso da elaboração/construção dos fatos científicos, o papel das metáforas não é tão evidente; no entanto, sua importância não é menor. Segundo a autora, as metáforas estruturam e organizam o trabalho de investigação, participando de forma essencial na construção do saber científico. Elas estão presentes desde o processo de teorização, onde, diante da ausência de palavras para dar corpo às ideias, o recurso à linguagem comum e ordinária torna-se, muitas vezes, imperativo. Além disso, como aponta Andrade (2010), as metáforas constituem a linguagem e o pensamento humanos, estando presentes em todos os discursos. As metáforas são parte intrínseca da ciência, configurando-se como elementos constituintes e indispensáveis ao discurso científico.

Um ponto relevante, que alça as metáforas a um importante componente de análise no caso aqui destacado, é indicado por Banzato (no prelo), em uma apropriação do trabalho de Lakoff e Johnson (1980). Muitos conceitos abstratos são entendidos por metáforas, mas um tipo delas, as metáforas ontológicas, envolve atribuir às propriedades do objeto um conceito abstrato. $\mathrm{O}$ exemplo dos autores é esclarecedor: frequentemente pensamos na memória como algo estocado na mente, sendo quase intuitivo tratar a memória como se fosse um objeto físico, o que, por consequência, traz consigo uma tendência objetivista de concebê-la como coisa estocada na mente. Essa tendência, no limite, leva a assumir que conceitos espelham um mundo feito de objetos específicos, bem delimitados, cujas propriedades são independentes dos propósitos daqueles que os descrevem. A grande questão em torno do problema da reificação ontológica no campo dos diagnósticos mentais, por exemplo, é que eles tomam os achados ainda em estudos nos ensaios clínicos, nos estudos de imagem, nas investigações neurocientíficas como espelhos da natureza, ou seja, como retratos fiéis de uma 
realidade capaz de ser equalizada com os transtornos mentais, sem sua dimensão

fenomenológico-experiencial, e tal como se apresenta para cada indivíduo.

\section{O cérebro e suas metáforas: contexto de formação}

A década de 1990, proclamada Década do Cérebro pelo então presidente norte-americano George Bush, assistiu a um aumento do interesse pelos estudos neurocientíficos, sobretudo pelos estudos de imageamento cerebral, como os PET-scans, ressonâncias magnéticas funcionais (CREASE,. 1993). Este período anunciou também a necessidade de incremento da consciência pública dos benefícios da pesquisa cerebral e do aprimoramento de atividades investigativas, já que milhôes de americanos eram cada vez mais afetados por doenças neurodegenerativas e outras moléstias ligadas ao cérebro. Deriva daí uma ascensão do campo das neurociências, um campo que reúne, como aponta AbiRached (2008), muitas subáreas diferentes, como a neurociência molecular, a genética psiquiátrica, a neurogênese, o imageamento cerebral, o desenvolvimento de medicamentos psicofarmacológicos, dentre outras.

A ressonância magnética funcional tornou possível acompanhar, praticamente em tempo real, a ativação cerebral, ou seja, para que áreas o sangue se desloca. A detecção de eventos que ocorrem em grande velocidade no cérebro ampliou as possibilidades de emprego da técnica de ressonância magnética funcional para o estudo de fenômenos que se aproximam do tempo real da atividade cerebral. Nesse sentido, esse exame tornou possível caracterizar correlatos neurais específicos de sintomas que têm grande variabilidade, por se tratar de uma técnica que avalia a atividade cerebral de forma dinâmica. Todo esse contexto aponta a difusão da crença no cérebro para explicar o que somos. As neurociências são chamadas, cada vez mais, a fazer prescriçõos de como viver, a organizar setores da sociedade e a ditar o que é o bem-viver. ${ }^{1}$

Segundo Contenças (1999), em cada época, uma metáfora dominou o pensamento científico, da mesma forma que o pensamento político, econômico e mesmo filosófico. De acordo com a autora, entre o século XVII e a primeira metade do século XVIII, a metáfora da máquina dominou a ciência, sendo utilizada para explicar desde o funcionamento do sistema solar até a dinâmica dos seres vivos e seus cérebros. Posteriormente, no século XIX, a metáfora do 
organismo tornou-se prevalente (CLARKE; JACYNA, 1987). Esta passagem da metáfora da máquina para a do organismo gerou, segundo Contenças (1999), uma dominância do natural sobre o artificial. Nesse contexto, "as máquinas passaram a ser descritas como organismos e as imagens orgânicas foram substituindo as imagens mecânicas" (CONTENÇAS, 1999, p. 71). No entanto, a autora aponta que ainda que essas metáforas globalizantes mudem, a influência de cada uma delas pode se estender para além de seu período dominante. Este é o caso da metáfora da máquina, que, após seu apogeu no século XVIII, transfigurou-se sob outras roupagens até a atualidade. Como aponta o relato de Rodney Books colocado como epígrafe deste trabalho, o cérebro já foi descrito no decorrer da história utilizando-se das metáforas da máquina hidráulica, do relógio e da máquina a vapor. Posteriormente, foram utilizadas as metáforas da central telefônica, do computador e, finalmente, da internet. Outras metáforas mecânicas certamente virão.

No livro de divulgação científica Cérebro, O'Shea (2010, p. 9) se refere ao órgão como a "máquina mais perfeitamente complexa e extraordinária no universo". Não fica claro, neste momento, a qual máquina exatamente ele se refere, mas que se trata de uma máquina incrivelmente complexa, capaz, inclusive, de refletir sobre si mesma e gerar consciência. Mais à frente o autor afirma que o cérebro, sendo uma "máquina admiravelmente evoluída e complexa", costuma ser comparado às "mais complexas máquinas feitas pelo homem: os computadores digitais" (p. 12). No entanto, afirma que tal comparação não é completamente válida, especialmente pelo fato de o cérebro ser constituído de matéria orgânica e os computadores, de matéria inorgânica. Para ele,

[...] parece muito improvável que o cérebro esteja apenas realizando algoritmos computacionais ou que o raciocínio possa ser atingido da mesma maneira com engrenagens e alavancas no lugar de células nervosas. Portanto, talvez não se possa esperar que os computadores tenham os mesmos desempenhos dos cérebros, a menos que haja uma maneira de construí-los em um meio biológico (O’SHEA, 2010, p. 12).

Desta forma, a metáfora do computador, ainda que válida sob alguns aspectos, não parece dar conta da complexidade do cérebro humano.

Em função destas limitações, mais recentemente alguns neurocientistas passaram a se utilizar de outra metáfora: a internet - que se relaciona ao modelo do cérebro como rede. Como apontam Graham e Rockmore (2011, p. 267 tradução livre): 
A metáfora do computador serviu bem à ciência cerebral como ferramenta para a com-

preensão dos sistemas neurais. Ainda assim, nós propomos aqui que essa metáfora seja substituída ou suplementada por uma nova metáfora, a "Metáfora da Internet", para refletir uma compreensão teórica de rede dramaticamente nova da estrutura e função cerebrais. Nós oferecemos uma forma "fraca" e uma forma "forte" dessa metáfora: a primeira sugere que as estruturas e os processos singulares às arquiteturas parecidas com a Internet (por exemplo, domínios e protocolos) podem guiar frutiferamente nosso pensamento sobre cérebros, ao passo que a última sugere que uma característica particular da Internet - a troca de pacotes (packet switching) - pode se materializar na estrutura de certas redes cerebrais, particularmente no neocórtex de mamíferos.

A representação do cérebro enquanto uma rede associa-se, ainda, a um entendimento cada vez menos localizacionista e mais associacionista do sistema nervoso central. Como afirma o neurocientista Nicolelis (2011), em seu livro de divulgação científica Muito além do nosso eu, um neurônio não pode mais ser visto como a unidade fundamental do sistema nervoso. Segundo ele, as pesquisas atuais apontam para o "fato inexorável de que populações de neurônios são os verdadeiros compositores das sinfonias elétricas que dão vida a todos os pensamentos gerados pelo cérebro humano" (NICOLELIS, 2011, p. 21). Para ilustrar sua perspectiva associacionista, ele se utiliza da metáfora da orquestra, onde o trabalho é realizado em rede e o resultado, a sinfonia - uma sinfonia neuronal -, é muito mais complexo do que a mera soma das partes. Outra metáfora utilizada pelo neurocientista é a de uma manifestação popular em que o coro de vozes obtém maior ressonância do que cada voz isoladamente. Segundo ele, da mesma forma que em uma manifestação, o cérebro "precisa contar com milhares de células cantando conjuntamente a cada instante para ter a esperança de saber o que fazer no momento seguinte" (NICOLELIS, 2011, p. 33).

Relacionado a esta perspectiva associacionista assim como à descoberta da neuroplasticidade, uma metáfora que tem se propagado cada vez mais é a de que o cérebro, sendo um músculo, pode e deve ser treinado, exercitado, malhado, estimulado, tornando-se saudável, jovem, forte, poderoso, turbinado - do contrário, envelhecerá e até mesmo perecerá (como sugere o livro Mantenha seu cérebro vivo). O cérebro é cada vez mais entendido - ver, por exemplo, Doige (2011) - como um órgão plástico, elástico, que se transforma, que pode ser remodelado, reeducado através de exercícios específicos para deixá-lo em forma. Essa ideia está presente em uma série de livros de neuróbica (ORTEGA, 2008), como por exemplo: Aumente o poder do seu cérebro, Aumente o desempenho do seu cérebro, Turbine seu 
cérebro, Mente e cérebro poderosos, Treine sua mente, mude seu cérebro, Reeduque seu cérebro, remodele seu corpo, Deixe seu cérebro em forma etc. ${ }^{2}$ Esta perspectiva plástica do cérebro vai na contramão de sua compreensão mecanicista, ainda influente, como apontado acima. Máquinas não são nem podem ser plásticas, órgãos, sim. Desta forma, o modelo organicista do cérebro coexiste com outras perspectivas mecanicistas.

Outra metáfora bastante forte e disseminada sobre o cérebro é aquela que o compreende como o órgão-sede da razão, do pensamento e do raciocínio lógico, contrapondo-o ao coração, sede das emoções, das paixões e dos sentimentos e, portanto, de tudo o que é irracional. Esta noção, que opõe o cérebro/razão ao coração/emoção, que já se encontrava em Aristóteles há mais de dois mil anos (CANGUILHEM, 2006), permanece nos dias de hoje, a despeito das formulações neurocientíficas que estabelecem o cérebro como sede tanto da razão quanto das emoções, sendo o coração apenas o órgão responsável pelo bombeamento de sangue. Talvez a permanência da visão do coração como o órgão das emoçôes se mantenha, dentre outros motivos, devido ao fato de não sentirmos o cérebro pulsar da mesma forma que nosso coração. Como afirma o filósofo Paul Ricoeur (apud AZIZE, 2010), o cérebro não faz parte - ainda - da nossa experiência corporal (bodily experience), sendo mais um objeto da ciência do que da nossa experiência cotidiana. Azize (2010), debatendo esta perspectiva de Ricouer, afirma que com a popularização do discurso neurocientífico pode acontecer de o cérebro tornar-se parte da experiência corporal cotidiana. Talvez no futuro, possamos sentir nosso cérebro da mesma forma que sentimos hoje nosso coração.

Finalmente, não é incomum encontrar em materiais voltados para o público leigo, expressões que antropomorfizam o cérebro, ou mesmo que o tomam mais como metonímia do que como metáfora, fazendo da parte, o todo, tais como o cérebro escolhe, o cérebro faz, o cérebro pensa, o cérebro aprende etc., como se o cérebro tivesse vida própria e tomasse as próprias decisóes, a despeito de seu dono. Nota-se uma completa identificação do que somos com o nosso cérebro. Crítico desta visão, o neurocientista Steven Rose (2012) afirma que falar que o "cérebro pensa" é equivalente a dizer "a perna anda". Para ele, "nós" pensamos através do cérebro, assim como andamos "com" nossa perna.

Essas equivalências entre identidade e cérebro ganham sentido no contexto já bastante explorado na década de 2000, segundo o qual o cérebro vem se tornando, 
mais do que um objeto científico e médico, um verdadeiro ator social, assumindo papel de destaque na constituição da identidade pessoal (EHRENBERG, 2009; VIDAL, 2004, 2009, 2011; ORTEGA; VIDAL, 2007; ORTEGA, 2007). O cérebro passa a ser cada vez mais compreendido como o único órgão do corpo absolutamente imprescindível para que sejamos nós mesmos, o que aponta para uma crescente identificação do que somos com nosso cérebro. Como afirma Ferret (1993 apud ORTEGA; VIDAL, 2007), "uma pessoa P é idêntica a uma pessoa $\mathrm{P}^{*}$ se e somente se $\mathrm{P}$ e P* são dotadas de um só e o mesmo cérebro funcional". Assim, num hipotético transplante de cérebro, o que estaria sendo realizado, na verdade, seria um transplante de corpo, haja vista o entendimento do cérebro como o órgão do eu por excelência. Nesse sentido, como contraponto à noção de personalidade, que designa a condição de ser uma pessoa, Vidal (2009) propõe o neologismo "cerebralidade" (brainhood) para designar a propriedade de não somente ter, mas de ser um cérebro.

Essa noção de que somos o nosso cérebro está relacionada ao desenvolvimento, especialmente a partir da segunda metade do século XX, do que alguns autores denominam de sujeito cerebral, "figura antropológica que incorpora a crença de que o ser humano é essencialmente reduzível a seu cérebro" (ORTEGA; VIDAL, 2007, p. 256). Esta figura aponta para a ascensão de discursos e práticas que concebem o cérebro como o órgão fundamental na construção da identidade e da subjetividade. Nesse contexto, crenças, desejos e comportamentos passam a ser descritos a partir de um vocabulário cerebralista. Rose $(2003$; 2007) chama de self neuroquimico (neurochemical self) justamente este movimento em que passamos a entender nossas mentes e selves em termos dos nossos cérebros e corpos (ROSE, 2003, p. 46). Dumit (2003, 2004), na mesma direção, designa de selves objetivos, o "conjunto de atos que dizem respeito aos nossos cérebros e aos nossos corpos derivados de fatos recebidos (received-facts) da ciência e da medicina" (2003, p. 39 - tradução livre). O fato de sabermos que temos um cérebro e que ele é necessário para sermos o que somos é um dos aspectos da objetificação de nosso self. Segundo o autor, o desenvolvimento das tecnologias de neuroimageamento contribuiu de forma significativa para a construção dessa nova compreensão, objetificada e externalizada, do próprio corpo e de si mesmo. Outros autores apontam, na mesma direção, para um amplo processo social de somatização e exteriorização da subjetividade em curso na contemporaneidade. 
Diante de tantas metáforas fisicalistas para o cérebro, é mister situar o movimento do que se tem chamado de CriticalNeuroscience, interessado justamente nesses diversos usos e metáforas que o cérebro tem adquirido na cultura popular de massa. O ponto comum entre seus autores (ver CHOUDHURY; SLABY, 2012) é uma indignação a respeito do apelo excessivo do cérebro como "revelador de sentido" de questôes nas mais diferentes áreas do cotidiano da vida, muito além do laboratório. Levando a sério a relevância, mas rejeitando a primazia do cérebro no entendimento do comportamento, o grupo referido se centra numa análise crítica do processo acima referido, perguntando-se de que modo é possível contribuir para uma teoria mais complexa e rica, e para explicações mais nuançadas do comportamento, onde o cérebro seja uma condição necessária, mas não exclusiva para a explicação dos fenômenos do comportamento. A chamada "neurociência crítica" emerge, portanto, para responder à velocidade tremenda do desenvolvimento das neurociências durante as últimas duas décadas e, em particular, ao crescimento de ênfase nos achados neurocientíficos sobre a vida social e cultural dos seres humanos, além do emergente interesse na medicina, na educação, na lei, na política - isto é, de sua propagação na vida cultural das sociedades urbanas liberais do Ocidente.

Seus autores - conhecedores dos impactos e dos sentidos metafóricos que o cérebro alcança também no contexto brasileiro ${ }^{3}$ para explicar a vida cotidiana propõem que as neurociências não são apenas um campo em extensão, mas um campo de controvérsias dentro da esfera acadêmica. Há, como resultado disso, diferentes vozes - algumas alegando a defasagem sócio-histórica das pesquisas neurocientíficas, outras, seu potencial revolucionário (MALABOU, 2008), e outras, a característica controversa dos resultados de pesquisas no campo das neuroimagens (VUL et al., 2009).

Certamente, ninguém duvida de que estamos muito melhores em nosso conhecimento sobre processos no cérebro tanto na saúde quanto na doença desde a explosão dos estudos sobre o cérebro, na década de 1990. É preciso reconhecer, no entanto, que ainda estamos longe de alcançar um entendimento do cérebro que seja realmente capaz de mudanças notáveis em nossas vidas em termos de nossas práticas, nossas instituições, nossas tecnologias. Além disso, não está claro como os processos neurais que estamos conhecendo são capazes de desvendar 
a experiência subjetiva, as particularidades da narrativa em primeira pessoa e outros detalhes que dependem do cérebro, mas não somente dele.

O grupo referido está atento para o fato de que o processo de vulgarização do conhecimento sobre o cérebro traz certo tom acrítico dos resultados, achados e imagens. Muitos neurocientistas têm tentado atingir públicos maiores entre especialistas, e a audiência leiga para disseminar os achados, aumentar o conhecimento público sobre o cérebro, as agências de financiamento encorajam o engajamento público como parte da pesquisa científica e as editoras universitárias se engajam em mostrar achados à mídia. É nesse ponto crucial que as "metáforas" superdimensionam as promessas das neurociências, deixando de lado seus limites. Entre as ferramentas conceituais utilizadas por esse grupo estão: por um lado, uma rejeição do cientificismo reducionista e individualista que se diferencia da cultura do conhecimento e da sociedade e permeia muito da literatura do que se chama "neuro-hype"; por outro, o objetivo de trabalhar numa abordagem integrada com comportamentos que situam o cérebro e a cognição no corpo, no mundo social e no mundo político. Assim, a noção de crítica empregada na Neurociência Crítica entende que a pesquisa neurocientífica é um campo de controvérsias, e não de promessas revolucionárias em vias de serem cumpridas.

O objetivo do que se pode chamar de "neurociência crítica" e que nos parece crucial para situar e compreender as metáforas pelas quais o cérebro é divulgado na amostra analisada é a de podermos manter a atitude ponderada, como pesquisadores, de não celebrar inadvertidamente as neurociências em cada um de seus achados, nem condená-las como um todo. Isso porque, de acordo com essa perspectiva, não é somente o que está sendo alegado pela neuroindústria, ou seja, pela maquinaria que nos fornece por diferentes formas de mídia, o que merece atenção e análise, mas o próprio fato de que as alegações neurocientíficas estão em suspenso e são um campo em processo.

\section{Consideraçôes finais}

Uma análise das condições de como um "fato cerebral” aparece e é levado ao público de massa nos leva além da questão se os resultados das neurociências podem realmente preencher suas promessas, nos impelindo a explorar as razões de como e por que os achados numa ciência em desenvolvimento são difundidas 
como um presságio de reinvenções radicais das noções de natureza humana e estruturas das instituições sociais. O projeto de uma neurociência crítica é o de compreender as neurociências como um campo de saber historicamente situado, envolvido em um campo sociocultural mais amplo onde interagem forças relevantes como a indústria farmacêutica, as companhias de seguro, as alegaçóes e pleitos dos pacientes. $\mathrm{O}$ ponto em comum entre seus adeptos é a reflexão sobre os "achados científicos sobre o cérebro", sem tomá-los como inevitáveis, universais e transistóricos. O objetivo seria, portanto, trabalhar numa abordagem integrada entre neurociências e ciências humanas e sociais para compreender comportamentos humanos. Não seria possível nem desejável, assim, o estudo do cérebro isolado, mas constitutivamente inserido e encarnado no seu ambiente (GALLAGHER, 2005; HAUGELAND, 1998).

Assume-se, assim, que o processo mental é constitutivamente encarnado, imerso no seu ambiente e não pode ser caracterizado sem referência às relações da dimensão corporal com o ambiente físico e social. (HAUGELAND, 1998; GALLAGHER, 2005). A pressuposição de uma separação entre experiência (percepção, emoção, sensação) e ação é abandonada em favor de um entendimento da ação da experiência incorporada. (BROOKS, 1991; CLARK, 1997; HURLEY, 1998; NOË, 2005; O’REGAN, NOË, 2001). O resultado é uma imagem mais integrada e holista do agente cognitivo constituído em imersão no seu ambiente. Outro foco é a questão da intersubjetividade: a experiência humana consistiria em modos de relação com o mundo que são socialmente partilhados enquanto a própria experiência do mundo é, nesse sentido, revelada como uma vida social.

Diante dessa perspectiva, quais seriam, em nossa amostra, as metáforas que vemos espalhadas com efusão pelo espaço sociocultural brasileiro? Por que algumas metáforas vingam e se diluem popularmente mais que as outras, aqui consideradas minoritárias? Essas são questões para promover o debate, mais do que para serem respondidas. Nesse sentido, a neurociência crítica emerge como uma perspectiva sobre o cérebro que não aparece como metáfora no material analisado, como será analisado, mas que se mostra uma abordagem existente e possível oferecendo visões mais ampliadas e mais complexas se levamos em conta os ganhos com a compreensão teórica e prática da relação do organismo com o cérebro e deste com seu meio. A perspectiva de um "cérebro situado e inserido em seu meio sócio-histórico”, tal como aparece na perspectiva da neurociência 
crítica, é inexistente na amostra investigada. Como é constantemente enfatizado

pelo grupo da Neurociência Crítica, romper com o legado mentalista que assume dicotomias como mente/corpo, corpo/mundo, mente individual/mente dos outros é, certamente, uma perspectiva em contraste, senão em controvérsia com a do sujeito cerebral e suas já assinaladas metáforas.

Sem celebrar as neurociências acriticamente ou condená-las como um todo, o grupo ao qual fazemos referência opta teórica e eticamente por contextualizar os objetos de pesquisa - seja ele a adição, a sociabilidade, a empatia, a cooperação, o comportamento dos adolescentes - apontando que os achados científicos são mantidos por uma variedade de fatores, coproduzidos por diversas circunstâncias, interesses, instituiçõos, aos quais o cérebro, tout court não é suficiente como forma de resposta.

O presente trabalho pretendeu levantar e analisar brevemente algumas metáforas sobre o cérebro encontradas em alguns livros de divulgação científica, traçando um panorama das principais metáforas encontradas no material analisado. Nossas conclusões apontam para uma certa compreensão do cérebro como destacado do organismo que aprende, do ambiente em que o organismo está imerso, como se tal órgão assumisse, sozinho e privilegiadamente, o papel de perceber, conhecer e aprender. Como nos informa Contenças (1999), as metáforas estão intrinsecamente ligadas à produção e comunicação científicas.

No caso das neurociências, que avançaram enormemente em termos de conhecimentos nas últimas décadas e que, além disso, têm se popularizado de forma crescente, é inevitável que metáforas sejam utilizadas por cientistas, jornalistas e leigos para descrever o cérebro. A perspectiva da Critical Neuroscience nos serve, ao final, como sugestão para manter a controvérsia do campo e do debate, e para a sugestão de uma metáfora que não foi encontrada em nossa amostra, qual seja, a do cérebro como condição necessária, mas não suficiente para comportamentos superiores humanos. ${ }^{4}$

\section{Referências}

ABI-RACHED, J.M. The new brain sciences: field or fields? Brain Self and Society Working Papers, v. 2., London, 2008.

ALAC, M. Negotiating pictures of numbers. Social epistemology, n. 2-3, p. 199-214, 2004. ANDRADE, A.D. de. A Metáfora no discurso das ciências. Dissertação (Mestrado em Letras) 
- Faculdade de Filosofia, Letras e Ciências Humanas, Universidade Federal de Pernambuco, Recife, 2010.

AZIZE, R.L. A nova ordem cerebral: a concepção de "pessoa" na difusão neurocientífica. Tese (Doutorado em Antropologia Social) - Museu Nacional, Universidade Federal do Rio de Janeiro, Rio de Janeiro, 2010.

BANZATO, C.E.M. Reification. In: CAUTIN, R.; LILIENFELD, S. The Encyclopedia of Clinical Psychology. Wiley-Blackwell. In press. 2014.

BEAULIEU, A. Voxels in the brain: neuroscience, informatics and changing notions of objectivity. Social Studies of Science, v. 31, n. 5, p. 635-80, 2001.

BROOKS, R.A. Intelligence without representations. Artificial Intelligence, n. 47, p. 139159, 1991.

CANGUILHEM, G. O cérebro e o pensamento. Natureza Humana. São Paulo, v. 8, n. 1, p. 183-210, 2006.

CHANGEUX, J.-P. Neuronal man: the biology of mind. Princeton University Press, 1997.

CHURCHLAND, P.S. Neurophilosophy: Toward a unified science of the mind-brain. Cambridge: MIT Press, 1989.

CLARK, A. Being there: putting brain, body and world together again. Cambridge: MIT Press, 1997.

CLARKE, E.; JACYNA, L.S. Nineteenth-Century Origins of Neuroscientific Concepts. Los Angeles: University of California Press, 1987.

CONTENÇAS, P. A eficácia da metáfora na produção da ciência: o caso da genética. Lisboa: Instituto Piaget, 1999.

COSER, O. As metáforas farmacoquímicas com que vivemos: ensaios de metapsicofarmacologia. Rio de Janeiro: Garamond, 2010. p. 144

CREASE, R.P. Biomedicine in the age of imaging Science, n. 261, p. 554-561, 1993.

DOIGE, N. O cérebro que se transforma: como a neurociência pode curar as pessoas. Rio de Janeiro: Record, 2011.

FOUCAULT, M. Madness and civilization: A history of insanity in the age of reason. New York: Vintage, 1973.

GRAHAM, D.; ROCKMORE, D. The packet switching brain. Journal of Cogntive Neuroscience. v. 23, n. 2, p. 267-76, 2011

HACKING, I. The looping effect of human kinds. In: SPERBER, D.; PREMACK, A.J. (Eds.). Causal cognition. Oxford: Oxford University Press, 1995. p. 351-383.

HACKING, I. The social construction of what? Cambridge: Harvard University Press, 1999. 
HURLEY, S.L. Consciousness in action. Cambridge: Harvard University Press, 1998.

KOSSLYN, S. If neuroimaging is the answer, what is the question? Philosophical Transactions. Biological Sciences. v. 354, n. 1.387, p. 1.283-1.294, 1999.

LAKOFF, G.; JOHNSON, M. Metaphors we live by. Chicago: The University of Chicago Press, 1980.

MALABOU, C. What should we do with our brain? New York: Fordham University Press, 2008.

MALAVOY, S. Guia prático de divulgação científica. Rio de Janeiro: Fiocruz, 2005.

NICOLELIS, M. Muito além do nosso eu. São Paulo: Cia das letras, 2011.

NOË, A. Action in perception. Cambridge: MIT Press, 2005.

O'REGAN, J.K.; NOË, A. A sensorimotor account of vision and visual consciousness. Behavioral and Brain Sciences, n. 24, p. 939-1011, 2001.

O’SHEA, M. Cérebro. Porto Alegre: L\&PM, 2010.

ORTEGA, F. Neurociências, neurocultura e autoajuda cerebral. Interface, Botucatu, v. 13, n. 31, p. 247-260, 2009 .

. O sujeito cerebral e o movimento da neurodiversidade. Mana. Rio de Janeiro, v. 14, n. 2, p. 477-509, 2008.

ORTEGA, F.; VIDAL, F. Mapping the cerebral subject in contemporary culture. RECIIS: Revista Eletrônica de Comunicação, Informação e Inovação em Saúde. Rio de Janeiro, v. 1, n.2, p. 255-259, 2007.

PROTEVI, J. Political affect: connecting the social and the somatic. Minneapolis: University of Minnesota Press, 2009.

ROSE, S. The need for a critical Neuroscience: from Neuroideology to Neurotechnology. In: SLABY, J.; CHOUDHURY, S. (Eds.). Critical Neuroscience: a handbook of the social and cultural contexts of Neuroscience. New Jersey: Wiley-Blackwell, 2012. p. 53-66.

SLABY, J.; CHOUDHURY, S. (Org.) Critical Neuroscience: a handbook of the social and cultural contexts of Neuroscience. New Jersey: Wiley-Blackwell, 2012.

SONTAG, S. Doença como metáforal A AIDS e suas metáforas. São Paulo: Cia das Letras, 2007.

TAYLOR, C. Self-interpreting animals. In: Philosophical Papers. Cambridge:

Cambridge University Press, 1985. p. 45-76.

Sources of the self: The making of the modern identity. Cambridge: Harvard University Press, 1989. 
VIDAL, F. Brainhood, anthropological figure of modernity. History of the Human Sciences, v. 22 , n. 1, 5-36, 2009.

- Le sujet cérébral: une esquisse historique et conceptuelle. Psychiatrie, sciences humaines, neurosciences, v.3, n. 11, p. 37-48, 2005.

VUL, E. et al. Puzzlingly high correlations in FMRI studies of emotion, personality, and social cognition. Perspectives on Psychological Science, v. 4, n. 3, p. 274-290, 2009.

\section{Notas}

${ }^{1} \mathrm{O}$ brain capital é, por exemplo, um projeto que serve como paradigma para as tendências recentes das neurociências de inspirarem políticas e iniciativas em cenários neoliberais. Ver: http://www. braincapitalgroup.com (acesso em: set 2013).

${ }^{2}$ Algo interessante, que transparece em alguns destes títulos, é que a noção de mente permanece no discurso neurocientífico, mas, da mesma forma que o coração metafórico, submetido ao cérebro ou então como mero produto de suas atividades.

${ }^{3}$ No Brasil, exemplo claro disso são os programas dirigidos à divulgação científica, como o quadro NeuroLógica exibido entre 2008 e 2009 no programa Fantástico, da Rede Globo sob coordenação da neurocientista Suzana Herculano-Houzel.

${ }^{4}$ F.S. Lisboa participou da concepção do manuscrito, da coleta de dados bibliográficos, da análise, da revisão de literatura e da redação. R.T. Zorzanelli participou da revisão de literatura, da redação e da revisão crítica relevante do conteúdo intelectual. 


\section{Abstract}

\section{Metaphors of the brain: a reflection on the representations of the human brain in contemporaneity}

In this paper we intend to present and discuss some metaphors of the human brain present in a sample of materials of science communication aimed, therefore, to reflect on meanings and uses associated with the human brain. In the case of the scientific dissemination, in which scientists and science journalists seek to translate or recreate to the lay public the scientific knowledge, the importance of metaphors is evident as they approach the lay public of certain meanings attributed by the promoters of science on the functioning of the brain. Finally, we analytically discuss a few points of contact between the metaphors found.

Key words: metaphors; brain; neurosciences; scientific dissemination. 